\title{
Encontro na cidade: práticas de se habitar como vínculos para a produção de cuidado pelas ruas
}

\author{
City meeting: urban living practices \\ as bonds for the production of care in the streets
}

Pedro de Andrade Calil Jabur (https://orcid.org/0000-0001-5921-8993) ${ }^{1}$

Cássio Henrique Oliveira da Conceição (https://orcid.org/0000-0002-1912-0550) ${ }^{2}$

Tâmara Rios de Sousa (https://orcid.org/0000-0002-2909-2418) ${ }^{1}$

${ }^{1}$ Universidade de Brasília. Campus Ceilândia, Centro Metropolitano I Conjunto

A, Ceilândia Sul. 72220900 Brasília DF Brasil.

pedrojabur@gmail.com

${ }^{2}$ Programa de Pós-

Graduação em

Desenvolvimento, Sociedade e Cooperação Internacional, Universidade de Brasília. Brasília DF Brasil.

\begin{abstract}
This paper aims to present the potential city dwelling tactics and strategies employed by People Living on the Streets (PLS) in Brasilia, Brazil, to reflect on the production of care and bonding within the Brazilian PHC (known as APS). First, we will discuss the broad sense of this notion of living as a set of everyday creations and innovations established as transient and circumstantial ways of creating bonds and care and as daily tools of health workers within the Brazilian Unified Health System (SUS). We will then present two PLS narratives to offer examples of actions performed in their homes built in the streets. The analysis of these encounters allows us to contextualize their lives on the streets, highlighting the movements that lead to the invisibility of this population and the precarious and fragile state of these practices and existences in and of the city. As a final perspective, we will point to the meeting of these living practices with the actions and technologies used by health workers in the process of self-care in the urban spaces.
\end{abstract}

Key words Urban spaces, People living on the streets, Primary Health Care
Resumo Este artigo tem como objetivo apresentar a potencialidade de táticas e estratégias de habitar a cidade utilizadas por pessoas em situação de rua, em Brasília (DF), como meios para se pensar produções de cuidado e vínculo junto à Atenção Primária à Saúde (APS). Primeiramente, discutiremos o sentido amplo dessa noção de se habitar como um conjunto de criações e inovações cotidianas que se estabelecem como formas passageiras e circunstais de criação de vínculos, $e$ cuidados e também como instrumentos cotidianos do trabalho da saúde dentro do contexto do Sistema Único de Saúde (SUS). Posteriormente, apresentaremos dois relatos de pessoas em situação de rua na intenção de exemplificar fazeres na cidade partindo de suas casas edificadas nas ruas da cidade. A análise desses encontros abre caminho primeiramente para a contextualização das vidas nas ruas destacando os movimentos que operam no sentido de invisibilidade desse contingente e as precariedades e fragilidades dessas práticas e existências na e da cidade. Como perspectiva final de análise, pontuaremos o encontro dessas práticas para se habitar com os fazeres e tecnologias utilizados pela saúde no processo de se cuidar pelos espaços da cidade.

Palavras-chave Espaço urbano, População em situação de rua, Atenção Primária à Saúde 


\section{Introdução}

Este artigo perpassa um conjunto de pesquisas com população em situação de rua realizadas desde 2016 por um coletivo de pesquisadores e professores das ciências sociais e da saúde coletiva. Destacaremos algumas entrevistas que, durante o processo de aproximação, conversas preliminares e criação de vínculos, a questão do uso e da construção de uma casa pelas ruas se tornou um dos mediadores centrais dos diálogos com esses sujeitos, inclusive através do convite dos próprios para conhecermos suas casas e histórias.

Nesse sentido, discutiremos primeiramente nesse artigo, como a ideia e a prática de se habitar numa cidade estão ligadas à noção de se ter o direito de usá-la através de seus espaços. Essa conjugação ampliada de se poder viver nos espaços urbanos necessariamente esbarra na própria concepção moderna do que é e para quem serve uma cidade.

A expressão direito à cidade, criada pelo sociólogo francês Henri Lefebvre' ${ }^{1}$, surgiu para denunciar que os espaços urbanos, já à época, haviam se convertido, espacialmente e simbolicamente, em locus de reprodução das relações capitalistas, marcadas por estruturas perversas de desigualdades. Direito à cidade necessariamente, segundo o autor ${ }^{1}$, seria a possibilidade de se viver em uma cidade onde a própria vida cotidiana torna-se o ciclo de mudanças do viver no espaço, fazendo com que todos os cidadãos possam participar de redes e circuitos da cidade, tornando-a assim obra em perpétuo uso de cidadanias.

Partindo de alguns dos caminhos elaborados pelo também sociólogo Richard Sennett ${ }^{2}$, mostraremos como a noção de habitar uma cidade passa então por usar seus espaços, aprendendo e aperfeiçoando constantemente saberes e táticas. Para o autor ${ }^{2}$, esses processos formam um habitar ético, pois são ações não atomizadas na figura de indivíduo, mas que demarcam na sua realização um sentido de coletividade. Utilizaremos as noções de usar, habitar, ter direito à cidade como sinônimos dessas táticas vinculares que buscam concreta e simbolicamente relacionar as vidas (humanas e não) e os espaços da cidade.

Táticas-éticas, que Mbembe ${ }^{3}$ acentua como a capacidade de se elaborar continentes capazes de abrigar conscientemente as condições fragmentadas das situações de vida, resultantes da extrema vulnerabilidade que passa a vida pelo mundo atual. Esses abrigos que cuidam são pontos de conexão com os próprios modos de a saúde habitar as cidades e operar em seus espaços e habitantes.
A seguir neste trabalho, apresentaremos duas entrevistas provindas de pesquisa de campo realizadas entre os anos de 2016 e 2019. Trazer a escuta de pessoas - que mesmo em situação de rua possuíam à época uma casa, contrariando uma denominação que as (des)qualificam - tenta, primeiramente, explicitar a complexidade do ato de se viver e ter o direito de habitar a cidade, embora estejam pelas ruas.

Destacaremos de suas falas justamente algumas dessas táticas de apropriação a despeito de todos os tipos de constrangimentos que é o de estar em situação de rua e ter uma casa fincada nesse espaço. Claudia Girola ${ }^{4}$ afirma que é necessário deixar de considerar a população de rua como uma espécie de retrato negativo da humanidade, analisada como um único conjunto indiferenciado de perdas. Para a autora ${ }^{4}$, a escuta e a análise dessas vidas devem tentar, baseada em uma atenção mais sensível, ultrapassar esse sentido primeiro de destruição, não para deixar de ouvi-las, mas para entrar em contato a formas outras de construção. Os relatos são produtos de três ou mais encontros com esses sujeitos e que cujas falas foram transcritas com a anuência dos entrevistados através do Termo de Consentimento Livre e Esclarecido. Seus nomes verdadeiros foram modificados, a pedido deles.

No ponto seguinte do artigo, como forma inicial de análise dessas práticas, contextualizaremos quem são os produtores diários dessas e de outros usos da cidade. Grande parte dessas formas de habitar são realizadas por um contingente cada vez maior de anônimos, muitas vezes classificados como em situação de rua para melhor assim (não) enxergá-los. Depois de dez anos da promulgação da Política Nacional para a População em Situação de Rua ${ }^{5}$, sem sabermos quem são e quantos são (existem, como mostraremos, estimativas), esses inventores anônimos percorrem, vivem e sobrevivem nas ruas das cidades se utilizando das mais variadas formas e táticas.

Esses construtores diários da cidade em suas ruas são justamente os que, intermitentemente, são constrangidos (em todos os sentidos) por agentes da ordem, da moral e da segurança, mas também da assistência, do cuidado e da fé, além dos representantes oficiais de revitalizações, reformas e processos de inclusão. Finalizaremos nossa análise discutindo como essas experiências são produtoras de vínculos e podem se encontrar pelas ruas através da atuação da Atenção Primária à Saúde (APS) como instrumento de captação e amplificação desses vínculos através da produção de cuidado ${ }^{6}$. APS será interpretada neste 
trabalho como uma forma de cuidado integral de saúde focado no usuário-cidadão, definido no Sistema Único de Saúde (SUS) brasileiro como ferramenta política e social para efetividade do acesso à saúde universal com equidade e integralidade, atuando de maneira contínua para a qualificação e completude destes princípios, a partir de ações multissetoriais, transdisciplinares, participativas $^{7,8}$. A construção conjunta de práticas de saúde no espaço urbano abre possibilidade de se reconhecer os cuidados que se adaptam, se modificam e por vezes se transformam sobre os verbos do habitar a cidade.

\section{Habitar como prática ética de produção de vínculos}

Em "Carne e Pedra”, Richard Sennett" demonstra algumas das várias analogias que foram desenvolvidas entre o corpo físico da cidade e o corpo humano baseadas no uso de metáforas orgânicas. Para o autor, parte considerável dessas analogias, que remontam ao final do século XVIII, serviram e servem para prender a cidade na imagem estereotipada de um corpo patológico, em que o planejamento urbano e seus técnicos seriam os únicos capazes de diagnosticar os males e de propor terapias. Essa relação engessa as possibilidades da vida na cidade se utilizando de uma mitologia higiênica, equilibrada, racional e eficiente, além de perpetuar uma lógica de que a vida na cidade passa por um saber técnico na mão de poucos e não na experiência de seus habitantes no dia a dia de uso de seus espaços.

$\mathrm{O}$ autor $^{9}$ usa como exemplo o próprio declínio do espaço e do homem público sob o incremento de formas cada vez mais presentes de privatização da vida urbana. $\mathrm{O}$ abandono da vida em comum faz desaparecer espaços e processos marcados pelos usos e saberes compartilhados de vida na cidade. A claustrobofia se torna um princípio ético na medida em que não existe nem disponibilidade nem lugares para se conviver com estranhos. A fuga das interações e dos espaços heterogêneos se desenvolve mais rapidamente a partir da segunda metade do século XX, e tem sido radicalizado com as transformações contemporâneas e seus impactos sobre as cidades.

Pensar em qualquer forma de direito à cidade, em formas de habitá-la, é estabelecer redes múltiplas com movimentos e temáticas múltiplas como transporte público, saneamento, educação, saúde, trabalho, habitação, saúde mental, velhice, sem teto, sem terra, emprego, LGBTQI+, população em situação de rua.
Nesse sentido, Sennett ${ }^{10}$, ao longo de várias de suas obras, sugere caminhos, inclusive metodológicos, para se passar a perceber a relação entre sujeitos e cidades e suas expressões de criação. Como forma de reverter essa ética da claustrofobia, o autor apresenta em várias de suas obras um infindável número de exemplos de usos e fazeres da e na cidade e busca no uso e no sentido das práticas menores, rituais que aparentam ser pequenos, muitas vezes anônimos, pistas para perceber as inventividades e lógicas em jogo no habitar a cidade.

Em "Construir e habitar: ética para uma cidade aberta”, esses caminhos são explicitados pelo autor ${ }^{2}$ ao elencar algumas práticas para se habitar uma cidade. A primeira seria a de tocar, ouvir, cheirar lugares, como os meninos pobres em Medelín na Colômbia e sua capacidade de se virar pelas ruas através de um roçar que possibilita, segundo o autor, o desenvolvimento de um conhecimento corporificado e intuitivo sobre a própria cidade. $\mathrm{O}$ conhecimento ambulante, segunda prática, está relacionado às possibilidades de encontros e convivência em lugares e territórios desconhecidos e suas potencialidades narrativas e curativas. Os dois últimos pontos conversar com estranhos e viver e redescobrir sua própria condição em lugares desconhecidos - se entrelaçam com os anteriores, ao abrirem caminhos para se viver situações e interações outras, às vezes repletadas de mal-entendidos e ambiguidades no sentido de enriquecer a experiência de aproximação e aprendizado com o outro e consigo, consigo e a cidade.

Além do caráter inventivo e concreto dessas práticas, Sennett ${ }^{2,9,10}$ demonstra que são produtoras de cooperação, fazeres que buscam vínculos materializados em encontros, na capacidade de escutar o outro e na possibilidade de diálogo. Os processos de isolamento causados por estruturas materiais de desigualdade, a precarização da vida e do trabalho, a perda da capacidade de diálogos e as várias e diversas formas de violência são exemplos, trazidos pelo autor, para explicitar uma dinâmica de corrosão de cooperação e da possibilidade de vida juntos. Por isso mesmo, os caminhos para se habitar uma cidade passam pela solidariedade, cooperação e produção de vínculos na intenção de potencializar suas capacidades de reabilitação do espaço e do homem público.

Uma nova lógica de se viver nas cidades pode ser formada pela costura dessas práticas de encontros, cooperação e cuidado como uma ética do habitar. Sentidos, que para Certeau ${ }^{11}$, são a "liberdade gazeteira das práticas" ao fazerem 
criar as resistências e as liberdades, assim como as narrações e as invenções possíveis do cotidiano. Para ele ${ }^{11}$, caminhar pelos espaços da cidade é a matéria-prima das táticas cotidianas por abrir diferentes formas de se usar e de se apropriar dos espaços por onde se passa. $\mathrm{O}$ ato de andar seria, dentro do sistema urbano, o mesmo que o de falar é para a língua e por isso é produção de perspectivas (aqui e lá; longe e perto), fonte de retóricas de caminhos com suas voltas, desvios, cálculos e estratégias. Dosse ${ }^{12}$ explica que habitar seria narrar a costura dessas caminhadas usando como linhas o cuidado e a reabilitação de memórias e experiências pela cidade

Linhas de cuidado, que perpassam a própria atuação do trabalho da saúde no espaço urbano e sua concepção produtora de formas e práticas de se trabalhar na cidade através do cuidado. Táticas que se desdobram no surgimento da medicina social e suas ações de controle do espaço e dos corpos na cidade ao se estabelecer como autoridade sanitária dos espaços ${ }^{13}$, ou no conjunto de fazeres que atravessam, por exemplo a atuação da APS, para trazermos a discussão para o contexto e para as cidades brasileiras.

Formatada como primeira porta de acesso, espaço de contato, encontros e estabelecimento de relações, nos quais todos os demais serviços de cuidado serão oferecidos ao sujeito, o fazer da APS provém de táticas descentralizadas e capilarizadas nos espaços das cidades; compondo um fazer recheado por formas de cuidado permeadas pelo desenvolvimento de relações naturalmente moldadas no diálogo, acolhimento e no vínculo ${ }^{14}$.

Capacidade de costura que é fundamental, como explica $\mathrm{Mbembe}^{3}$, para a criação de novas formas de cuidado com o mundo, uma espécie de ética do passante elaborada a partir da necessidade do ser humano assumir seu próprio estatuto de passagem em um contexto que generaliza a condição de fragilidade da vida do próprio planeta e de todos os viventes. Trata-se de uma ética porque passar não implica em atravessar espaços, lugares, cidades, países variados, mas é também o ato de costurar uma relação dupla de solidariedade e de despreendimento, partindo de uma experiência de presença e diferença e nunca de indiferença, por isso de cuidado. Para o autor, o espaço dessas tessituras são lugares das experiências de encontro com os outros que abrem espaço para uma autoconsciência, provinda não de um individuo singular, mas da resultante da própria relação de se habitar a cidade, a rua, o mundo.

A seguir, através dos relatos de Antônio, Marta e Júnior, apresentaremos algumas dessas táti- cas de produção de encontros que aconteceram e acontecem o tempo todo nas passagens e caminhadas pelos espaços da cidade. Vínculos que se produzem pelos encontros, casas que são espaços de abrigo e de sonhos, caminhos para se fugir da cidade e para outras vidas. Carnes e pedras que na sua fricção abrem também caminhos para que possamos no vínculo com o outro pensar novas táticas para se viver, trabalhar e pesquisar pelas ruas das cidades.

\section{Casa é bom para conhecer gente}

Encontramos Antônio por conta do tamanho de sua casa, composta de lonas de cores diferentes, telhas e duas antenas enormes com CDs dependurados em suas hastes, que refletiam a luz do sol criando uma espécie de miríade de reflexos desde longe. Aproximamos a pé e depois de nos apresentarmos, ele logo puxou dois sacos para sentarmos à beira do meio fio, protegidos pela sombra da árvore. Bastante articulado, nos conta que está na rua há mais de 30 anos e chegou em Brasília em 2010, depois de passar a pé por vários estados.

Percebendo que estávamos reparando na casa e no ipê que a cobria de amarelo, Antônio nos chama para entrar. A casa tinha três cômodos: um com fogão de acampamento e talhares, outro com livros, revistas, garrafas de vidro, e duas malas e outro com seu colchão. Apesar de todo o esmero, ele nos apresenta sua casa, primeiramente, a partir de sua provisoriedade.

Por agora eu estou aqui, mas já vem alguém para me tirar. Aí eu desmonto e monto em outro canto e se não der em outra cidade. Eu não quero confusão, eu recolho a parafernália e vazo. Estou na rua porque eu quero, então não vou ficar aqui, igual 'os pedra', magrelo, mendigando comida. Tenho casa, cozinha, biblioteca e banheiro, na moita mais próxima (risos) (Antônio).

Sentamos em uma espécie de junção dos três quartos e podemos ter a dimensão da grandeza da casa. Podiam estar ali, sentadas umas cinco ou seis pessoas adultas.

Minha casa é no céu aberto, como um submarino amarelo. Quem quiser chegar, a gente vê logo por esse periscópio no teto solar. De vez em quando, aparece uns aqui, a gente faz um meio a meio: eles arrumam a comida e eu cozinho. É bom sentar e trocar umas ideias. Tem sempre umas mulheres que chegam (sorri) e eu vou deixando ficar até me dar nos nervos. Mas tem umas figurinhas que já chegam na 'escrotidão'. Mando passear, ameaço dar com água quente na cara (Antônio). 
Antônio conta sobre como faz no dia a dia.

Eu saio todo dia para manguear uma grana no supermercado ou para ir atrás de material, revista. O que tem de valor, eu levo no carrinho, mas as coisas aqui nunca ninguém mexeu enquanto estou fora. Quando estou com cash no bolso entro no mercado e compro alguma coisa para cozinhar. Também tem um gerente deles lá que sempre arruma um saco com couve, com beterraba, cenoura. E ele acha a maior graça de eu ser o dono dessa casa. Fala das minhas antenas. Ele desacreditou que tenho fogão e cozinho e tem os quartos, a biblioteca, debaixo desse ipê. Isso é o que salva. Passo lá, logo cedo, antes de abrir e já garanto. Já chamei para vir me visitar, igual vocês fazem, mas nunca veio. O cara acha maior graça então vou deixando ele achar graça (Antônio).

De uma outra vez, ele nos conta,

Ano passado, eu instalei minha casa, lá atrás daquela faculdade, me tiraram de lá, eu dei um tempo pelos matos do Goiás, voltei e coloquei aqui. Eu não vou ficar dormindo no relento, ai exposto. Se for fazer uma pesquisa eu apanho menos da polícia e dos outros do que quem está largado pela rua. Sabe por quê? Porque eu tenho casa. A polícia, tem uns que chegam chutando, mas aí chuta quem tem e quem não tem casa, elas fazem no esporte da maldade. As paredes me protegem disso. Quando eu vejo que é polícia trabalhador, eu já ofereço um café para limpar a barra. Eles nem sentam (...) Já pensou eles sentarem? Sentar aqui em casa e tomar um café comigo, seria o meu prêmio. Ia colocar até placa (Antônio).

De uma outra vez, ele conta que as antenas com discos dependurados serviam para se comunicar com um grupo de amigos por rádio amador.

Eu tinha uma bateria de carro que ligava no rádio, arriou e eu estou com as coisas todas aqui paradas. Tenho amigos do Brasil todo até a fronteira com o Uruguai. Gosto de conversar, ficar ouvindo notícias que os outros dão do mundo. Deixei as antenas instaladas na esperança de arrumar a bateria. Mas aqui tem sempre gente chegando, para conversar, dividir café e comida. Semana passada veio um povo da universidade e ficamos conversando igual vocês, uma tarde inteira. Já fiz amizade com os guardas noturnos desses estabelecimentos todos aqui. Ficar num lugar assim, ter casa é bom para conhecer gente (Antônio).

Ainda encontramos com Antônio mais duas vezes antes de ele ser retirado do local.

\section{Casa para abrigar sonhos e tirar preocupações}

Marta, o marido, Júnior, e seus dois filhos vivem em uma casa grande, feita de lonas e madeiras, escorada junto a uma cerca de arame na beira de um terreno com mata fechado. Ali próximo, apoiadas na mesma cerca, existiam três outras casas mais simples, espaçadas uns dez metros entre elas. Eram as únicas pessoas ali de fora, reunidos em torno de uma fogueira baixa. Bastante desconfiados, demonstraram primeiramente bastante receio quando nos apresentamos como pesquisadores.

Ao explicarmos um pouco de nossos objetivos, conseguimos combinar um outro dia para voltar. Da outra vez, Marta estava só com os filhos. O marido, que possui uma charrete, estava fazendo a catação de material reciclável.

Perguntou se não gostaríamos de esperá-lo e ficou bastante surpresa, quando respondemos que gostaríamos de conversar com ela também e que nossa intenção era justamente conhecer um pouco mais da vida dela e da família. Com uma fala pausada e sempre preocupada com seus filhos, Marta nos conta um pouco sobre a vida enquanto varre o chão em volta da casa.

A gente é do Maranhão. Os meninos nasceram na vida. A mãe do Júnior morreu e ele foi ficando nervoso, daí levaram para a emergência e internaram. Não deu uma semana, ele bateu na nossa casa, falando pra gente sumir no mundo. Para cá, para Brasília viemos a pé lá da Bahia tem quase três anos. Mais de duas semanas de viagem. A gente ouviu que tinha trabalho de ajudante de pedreiro, mas não deu nada. Todo dia ele chega com uma ideia nova. Ele vai lá para dentro de casa e fica quieto e eu sei que é ele, quieto para pensar (...) Nunca construímos casa nessas nossas andanças. Aqui resolvemos contruir porque os meninos já estão grandes e isso é família, não somos da rua, temos uma casa: é o que eu falo sempre para eles (Marta).

Quando Júnior chega da catação, sua recepção é efusiva, nos convidando para dentro da casa, enquanto sua mulher balbuciava sobre a sujeira interna para receber visitas. Uma casa espaçosa, com o chão limpo, forrado com esteiras de vime, com dois quartos com colchões e outro espaço com um monte de malas e sacos de lona cheios.

Quero fazer uma casa melhor que essa quando voltarmos para o Maranhão. Na beira da praia. Já entendi que dinheiro para ter um terreno, eu não ter nunca, ainda mais na beira da praia. Então eu pelo menos invento onde vamos morar. Já peguei o jeito de construir, sou assistente de pedreiro (Junior). 
Um outro dia, também combinado previamente, encontramos Marta e um dos filhos. Júnior e o mais velho haviam saído para a catação.

Eu fico com medo de me apegar, porque se vem o caminhão aqui e leva tudo embora?! Ele quer voltar, para viver disso aqui que ele vive, desse jeito dessas casas construídas no meio do nada. Ele diz que assim é melhor e que não falta nada para nós. E não falta mesmo. Aqui?! Com nosso dinheiro e o que a gente tem, está bom demais. Está sempre limpa e bem cuidada. Mas se você perguntar, eu quero ter uma cozinha de verdade, poder receber visitas (Marta).

Bastante compenetrada em sua rotina, passamos um tempo conversando com Marta. Quando Júnior chega, dividimos o lanche que havíamos levado e ficamos conversando a sós com ele.

Resolvi construir essa casa para tirar as preocupações da Marta e por conta dos meninos. Já disseram para a gente tomar cuidado se não a assistência leva. Quando eles mandarem a gente ir embora, tem que ir. Mas tem os vizinhos aqui e todo mundo se ajuda. Do governo, nunca passaram aqui para perguntar se precisamos de algo ou se os meninos estão doentes, é só para destruir, chutar, queimar tudo (Junior).

Júnior nos chama de novo para dentro de casa para mostrar a "passagem secreta" que fez para seus filhos. Por detrás do colchão do quarto havia um pedaço de lona aberto que dá para uma passagem na cerca que faz o apoio de parte da parede da casa.

Aqui eles passam e ninguém vê. Não tem casa nessa Brasília que tem uma porta que dá passagem secreta para uma floresta. Eu falo isso para Marta que não tem dinheiro que compre isso, mas ela quer voltar para a gente arrumar uma casa de tijolo. Não tem aluguel que compre passagem para a floresta ou para uma praia, aberta para o mundo (Junior).

Ainda encontramos com a família de Marta e Júnior algumas vezes antes de eles partirem rumo ao Maranhão, quase seis meses depois do nosso primeiro encontro.

\section{Invisibilidades nas situações de ruas: inventores anônimos nas cidades}

Como colocam Hardt e Negri ${ }^{15}$, a multidão é o próprio nome da pobreza, como o seu devir, pois a noção de pobre não remete aos que não tem nada, mas à ampla multiplicidade de todos os sujeitos que estão inseridos precariamente nos mecanismos de produção. A multidão é sempre um corpo político aberto e por isso radical, "opondo-se tanto ao individualismo quanto ao corpo social exclusivo e unificado da propriedade". A miséria, explicam, não está em não possuir nada, mas na condição de se estar separado daquilo que é possível de se fazer, a falta de poder, de criar e de governar ${ }^{15}$.

Para os autores, os migrantes, os pobres, os precarizados são captados pelas estatísticas econômicas sempre a partir do negativo, nunca por suas potências, "deixando de lado as formas de vida, linguagens, movimentos ou capacidade de inovação por ele gerados ${ }^{15}$.

O próprio termo população em situação de rua e a sigla PSR, oficializados com a assinatura do decreto que promulgou a Política Nacional para a População em Situação de Rua ${ }^{5}$, são frutos tanto de uma elaboração estatal como de um processo de amadurecimento dos movimentos sociais na tentativa de luta por reconhecimento e direitos. Mesmo tentando dar conta de uma multiplicidade, essas situações necessitam de serem pluralizadas no intuito de enxergar quem está nas ruas das cidades brasileiras. A noção inclusa no documento se refere a um

Grupo populacional heterogêneo que possui em comum a pobreza extrema, os vínculos familiares interrompidos ou fragilizados e a inexistência de moradia convencional regular, e que utiliza os logradouros públicos e as áreas degradadas como espaço de moradia e de sustento, de forma temporária ou permanente, bem como as unidades de acolhimento para pernoite temporário ou como moradia provisória ${ }^{5}$.

Historicamente, como aponta Declerck ${ }^{16}$ existe sempre um movimento de "estabelecer distinções no sentido de classificar e hierarquizar e, ao mesmo tempo, colocar a distância" a surda e angustiante anomia dessa população"16. As identificações unitárias tentam dar conta de uma multiplicidade e fazem perceber contraditoriamente que os indigentes são sempre os outros, argumenta o autor.

Escorel ${ }^{17}$ demonstra que, na passagem das décadas de 1960 a 1970, os primeiros trabalhos e mesmo definições para a população de rua foram elaboradas se baseando nas noções de pobreza e miséria. Castelvecchi ${ }^{18}$ aponta que - já no final da década de 1970, com o surgimento de uma Pastoral de Rua e da Comunidade dos Sofredores, a denominação "sofredor de rua" passou a ser adotado inclusive pelos próprios sujeitos. A ideia era destacar uma situação de carência e fragilidade e apontar, desde então, a própria invisibilidade dessa população dentro das redes oficiais de saúde e de assistência social. $\mathrm{O}$ autor destaca que, somando-se a esse crescente contingente de pessoas vi- 
vendo na rua, passa a existir a figura do catador de lixo e objetos recicláveis e com isso a consequente organização dessas pessoas através da comunidade dos Sofredores de Rua.

Outras denominações aparecem e desaparecem de acordo com a fugacidade da própria rua. É comum entre aqueles que possuem uma casa, o uso do termo maloqueiro como referência à maloca ou mocó. Os que se utilizam de albergues são os albergados. Trecheiros ou pardais são nomeados a partir dos trabalhadores ou andarilhos que cruzam de uma cidade para outra ou de pequenas áreas agrícolas para outra ${ }^{19}$.

Esta riqueza de representações associadas à população em situação de rua se entrecruza com a própria multiplicidade das vidas em situação de rua. Espelhos de visibilidades e invisibilidades, as múltiplas situações de vida nas ruas ao mesmo tempo que são objetos de uma variedade de denominações estigmatizadoras, congelando comportamentos como desviantes ou características como forma de menosprezo e humilhação, abrigam uma parcela cada vez maior de trabalhadores precarizados e desempregados, compondo a ideia de multidão, explanada por Hardt e Negri ${ }^{15}$.

Atualmente, depois de pouco mais dez anos da promulgação da política nacional, somente uma única pesquisa foi realizada de forma oficial por parte do poder público federal. Publicada em 2008, através do antigo Ministério do Desenvolvimento Social e Combate a Fome, esse trabalho apresentou que à época cerca de 50 mil pessoas viviam em situação de rua no país, além de características do perfil e do cotidiano dessas pessoas.

Apenas em 2016, através de uma estimativa elaborada pelo Instituto de Pesquisa Econômica Aplicada (Ipea), utilizando-se de dados disponibilizados por 1.924 municípios via Censo do Sistema Único de Assistência Social (Censo Suas), registrou-se 101.854 pessoas em situação de rua. Em março de 2020, em pleno início da pandemia do novo coronavírus no país, os dados foram atualizados pelo mesmo instituto, constatando que a população em situação de rua cresceu $140 \%$ a partir de 2012, chegando a quase 222 mil brasileiros e tendendo a aumentar com a crise econômica acentuada pela pandemia da COVID-19. O estudo ainda cita que entre as pessoas sem moradia estão desempregados e trabalhadores informais, como guardadores de carros e vendedores ambulantes ${ }^{20}$.

Não se conhece o perfil dessa população - a não ser por estimativas de um número total, que não para de aumentar - e ela continua sendo reconhecida por um conjunto múltiplo de denomi- nações estereotipadas e percepções fragmentadas de seus perfis. Um dos caminhos previstos pela política nacional passaria justamente pelo cuidado, inclusive com uma única publicação de doze anos atrás de um manual de cuidado da população em situação de rua. A invisibilidade da população que está pelas ruas, impossibilitada muitas vezes de se abrigarem, esclarece uma lógica perversa: como falar de cuidado a essa população se não se sabe quem são, como são, o que pensam, e que táticas que utilizam para habitar os espaços das ruas da cidade.

Sempre assistidos e observados como um contingente populacional que demanda por saúde e assistência, a visão unitária de pessoas em situação de rua como sujeitos exclusivamente de demandas além de limitar o próprio sentido da aproximação e criação de vínculos, estrangula a noção de cuidado como uma relação unicamente centrada em uma noção de sujeitos em posições fixas de quem oferece e quem recebe.

Os relatos que apresentamos - além de exemplificar vários dos caminhos para se habitar uma cidade propostos por Sennett ${ }^{2,10}$ - são informes claros de práticas produtoras de vínculos e por isso mesmo de cooperação e cuidado. Desde o convite para conhecer suas casas por dentro, passando pelo cuidado envolvido na construção, manutenção, abrigo e precariedade, uma análise dos caminhos abertos pelos relatos de Antônio, Marta e Júnior perpassa o que Cassigoli ${ }^{21}$, chamou de transcendental concreto, que ao mesmo tempo que inaugura uma interioridade, indica também os vínculos potenciais entre o sujeito e o mundo. Por isso, explica, não é a casa e suas paredes que fazem o habitar, pois habitar, no seu sentido amplo, não se situa somente no mundo objetivo: ao contrário, é todo o mundo - objetivo e subjetivo - que se situa a partir do momento em que se habita os espaços de uma cidade.

\section{Táticas de cuidado, práticas de encontro}

Ao entrarmos nas casas, a provisoriedade e precariedade foram duas das constatações e qualificações iniciais que seus moradores se utilizaram para descrevê-las, não somente em razão da sua sustentação material como edificação no meio do espaço público, como também pela própria situação da vida de seus habitantes.

Vulnerabilidades que se materializam em todos os tipos de contextos ali expostos, mas que não paralisaram essas pessoas em uma espera pela hora de se perder violentamente tudo. Pelo contrário, a casa, como fluxo de interioridade e 
exteriores, se torna ponto de confluência de fazeres e encontros que abrem espaço para múltiplos pontos de vistas de em que se pode observar e analisar essas táticas para se habitar. Perspectivas reflexivas que, partindo da costura de falas e fazeres, nos possibilita analisá-las como as miríades de luzes refletidas pelas antenas de Antônio, que logo somem ou desaparecem com a mudança do sol, assim como as próprias construções.

Por isso, como espaço construído, é local, por exemplo, para Júnior poder imaginar fazer uma casa como aquela nas praias do Maranhão ou para Antônio constatar que sofre menos violência policial; como espaço da invenção, a casa extrapola suas paredes e se estende em conexões com o mundo, como uma passagem secreta para uma floresta como forma de se evitar a separação forçada de uma família.

Por outros caminhos, o espaço da rua visto de dentro da casa, faz dela uma tática de abrigo capaz de diferenciar através de suas paredes e periscópios quem chega e quem passa. Marta, por exemplo, elenca como razão para se contruir uma casa, o fato de serem uma família e não da rua. Por seu lado, Antônio consegue de longe com quem ele vai poder sentar e dividir comidas e histórias e relacionamentos.

Como explica Sucasas ${ }^{22}$ sobre a noção de casa para o filósofo Emmanuel Levinas, o habitar e a casa se constituem pontos nucleares de subjetivação, pois não existe fenomenologia de uma casa que não passe pela vontade de independência do espaço, expressão de vontade de durações e ontologias do devir.

Já a casa observada da rua se torna espaço de visibilidades e invisibilidades, pois ao mesmo tempo que tentam, se escondem do poder, do 'esporte da maldade', estão expostas como entroncamentos táticos. Produtores de encontro através de desejos de se tomar café com esse mesmo poder público, ou para que se pelo menos passe por ali para perguntar se todos estão bem.

Reflexos que são como habitares ao mesmo tempo invisíveis - expressões da existência frágil e instável da condição de passante ${ }^{3}$, e expostos, pelo conjunto de significados que se construir uma porta de entrada no meio da rua possui sob a condição de invisibilizado. Construtores anônimos de liberdade porque tentam romper a toda hora com o acidente que é o fato de estar preso a uma única situação (na rua), a partir inclusive dos convites e desejos de visitas.

Luzes que apontam dessas portas de entrada outras entradas vizinhas como as da Atenção Primária à Saúde, caminho de acesso do usuário ao conjunto de serviços oferecidos pela Rede de Atenção à Saúde (RAS). As visitas desejadas e sonhadas para conversas, cafés, agradecimentos e cuidados para além da proximidade e capilaridade desses fazeres da saúde, colocam como desafio às equipes a criação também de táticas para se habitar-trabalhar o cuidado nas cidades: instrumentos e formas inovadoras de vínculos, que perpassam práticas de construção de relações moldadas no diálogo e acolhimento mútuos.

O cuidado em saúde se materializa antes de mais nada nesses encontros. Franco ${ }^{23}$ aponta que o trabalho em saúde é movimentado inicialmente por encontros, que não se compõe como uma relação unidirecional e que muitas vezes extravasam a organização institucional que o serviço de saúde propõe. Posteriormente, esses encontros se transformam em fluxos de saúde que são "operativos, políticos, comunicacionais, simbólicos, subjetivos" $^{\prime 23}$, e se comportam da maneira necessária para materialidade do cuidado.

Ao desenvolver estudo sobre tratamento de tuberculose com pessoas em situação de rua, em São Paulo, Hino et al. ${ }^{24}$ destacam que as dificuldades de adesão dessas pessoas ao tratamento só pode ser analisado através de práticas e processos de formação de vínculo, tais como oficinas de artes, escuta qualificada e acolhimento.

Por isso mesmo, a prática de habitar a cidade conjuntamente com os usuários traz para a atenção primária a possibilidade de se compartilhar saberes em formas táticas, cuidado em forma de visitas às casas, criando assim espaço de abrigo de trabalhos conjuntos de cuidado em comum. Santos et al..$^{25}$ apontam que o trabalho da saúde nos territórios se concretiza através de ações nos próprios territórios, focadas para redução de estigmas, de preconceitos e de discriminação, tendo o acolhimento e o vínculo como instrumentos para sensibilizar redes para conhecer, aceitar e respeitar as diferenças, valorizar e apoiar

Como aponta Merhy ${ }^{26}$, o vínculo por sua centralidade e potencialidade nas operações diárias da saúde pode ser considerado como uma tecnologia leve de trabalho. Possibilidades de ações de saúde na cidade, que se agrupam como táticas de saúde para a cidade, pois o vínculo opera não apenas como processo de responsabilização pelo cuidado da saúde individual, mas coletivo, tomando a comunidade como usuário, e o vínculo como laço coletivo ${ }^{27}$.

Neste sentido, assim como habitar uma cidade acontece através do desenvolvimento de práticas, táticas e éticas, o trabalho da saúde na e da cidade também se utiliza de instrumentais. E assim como 
não existe uma única forma prática de se habitar a cidade, o vínculo não funciona sozinho como tecnologia leve no trabalho da saúde. A aproximação, o acolhimento, a escuta sensível e qualificada e a intenção cooperativa são exemplos de tecnologias leves como formas operativas para estabelecer essas relações de cuidado, promoção da saúde, prevenção da doença, adesão e continuidade de tratamentos.

Assim como coloca Sennett, as práticas para se habitar uma cidade são ações da carne nas pedras da cidade, táticas pequenas que produzem conhecimentos ambulantes transformando todos em construtores de espaços, ou como explica Antônio, peças operativas de uma casa que podem ser desmontadas e montadas em novos lugares ou em novas cidades, as tecnologias leves também são produzidas através do trabalho vivo em ato ${ }^{26}$, pois condensam em si as relações de interação e subjetividade, possibilitando produzir acolhimento e vínculo, como fazeres éticos de responsabilização e autonomização.

Os Agentes Comunitários de Saúde (ACS) são um dos exemplos de operadores diários, e muitas vezes anônimos, dessas tecnologias do trabalho da saúde no espaço da cidade, a partir da criação desses encontros. Pinto et al. ${ }^{28}$ afirmam que o protagonismo desses trabalhadores, denominados também a partir de uma sigla, está na capacidade para mediação, principalmente entre os saberes populares de saúde e os médicocientíficos, e para atuar como potencializador de encontros não apenas consigo e com os usuários, mas entre o serviço e a comunidade. Para Hallais e Barros $^{29}$, esse tipo de trabalho é capaz de produ- zir um tipo de cuidado descolonizador, porque está fundamentado no reconhecimento da diversidade e autonomia dos sujeitos, que permite, assim, a transformação do sujeito paciente-passivo em agente-participativo do seu processo de saúde, doença e cuidado.

Os fragmentos do habitar que desaparecem como possibilidades de mudanças sem despedidas. A casa como uma passagem para se tomar um folego longe das ruas, com tempo para sonhar, planejar, receber visitas, conhecer gente, se transformar em agente-habitante daquele lugar e naquele tempo. Tomada de posse momentânea para poder respirar e habitar, enquanto se cria vivências e sobrevivências nas cidades.

Em meio à crise de saúde global em razão da atual pandemia do novo coronavírus, esses espaços das cidades foram classificados como intransitáveis, mas nunca como inabitáveis a despeito das vidas, casas, práticas e táticas que estão toda hora vivendo, transformando e cuidando destes locais. Rios et al. ${ }^{30}$ constataram em uma revisão de estudos sobre a atual pandemia, a importância do vínculo 'coletivo' entre comunidade e profissionais/equipes de saúde, como forma de impulsionar "a colaboração comunitária para o isolamento social e medidas básicas de higiene respiratória"30.

Os encontros das portas abertas são possibilidades para se pensar esses e outros cuidados, pois, como são relações, práticas vinculares para se praticar carnes e pedras. Táticas e tecnologias leves de se fazer e carregar pelos espaços e que só funcionam na tenacidade dos usos cotidianos e anônimos de produção de saúde na e das cidades.

\section{Colaboradores}

PAC Jabur, CHO Conceição e TR Sousa colaboraram na pesquisa de campo, escrita e revisão do texto. 


\section{Referências}

1. Lefebvre. $O$ direito à cidade. São Paulo: Centauro; 2009.

2. Sennett R. Construir e habitar: ética para uma cidade aberta. $1^{\text {a }}$ ed. São Paulo: Editora Record; 2018.

3. Mbembe A. Políticas de Inimizade. Lisboa: Antígona; 2017.

4. Girola CM. Rencontrer des personnes sans abri. Une anthropologie réflexive. Politix [Internet]. 1996 [cited 2019 jun 5]; 9(34):87-98. Available from: https://www.persee.fr/doc/polix_0295-2319_1996_ num_9_34_1033

5. Brasil. Decreto $n^{0} 7053$ [Internet]. Brasília: Institui a Política Nacional para População em Situação de Rua e seu Comitê Intersetorial de Acompanhamento e Monitoramento; Dec 23, 2009. Available from: http:// www.planalto.gov.br/ccivil_03/_Ato2007-2010/2009/ Decreto/D7053.htm

6. Giovanella L, Almeida PF. Comprehensive primary care and segmented health systems in South America. Cad Saude Publica 2017; 33(Supl. 2):e00118816.

7. Giovanella L, Mendonça MHM. Atenção Primária à Saúde. In: Giovanella L, Escorel S, Lobato LVC, Noronha JC, Carvalho AI, editores. Politicas e Sistema de Saúde no Brasil. 2a ed. Rio de Janeiro: Editora Fiocruz; 2012. p. 746-833.

8. Giovanella L. Basic health care or primary health care? Cad Saude Publica 2018; 34(8).

9. Sennett R. Carne e Pedra - O corpo e a cidade na civilização Ocidental. $2^{\mathrm{a}}$ ed. Rio de Janeiro: Editora Record; 2001.

10. Sennett R. Juntos: os rituais, os prazeres e a política da cooperação. Rio de Janeiro: Editora Record; 2012.

11. Certeau M. A invenção do cotidiano - Artes de fazer. $5^{\mathrm{a}}$ ed. Petrópolis: Editora Vozes; 1994.

12. Dosse F. O Espaço Habitado Segundo Michel de Certeau. ArtCultura [Internet]. 2013;27:85-96. Available from: http://www.artcultura.inhis.ufu.br/PDF27/5.5_O_espaco_habitado_segundo_Michel_de_ Certeau.pdf

13. Foucault M. Microfísica do Poder. Rio de Janeiro: Graal; 1979.

14. Torres GMC, Figueiredo IDT, Cândido JAB, Morais APP, Almeida MI. O emprego das tecnologias leves no cuidado ao hipertenso na Estratégia Saúde da Família. Esc Anna Nery [periódico na Internet].2018 [acessado 2021 out. 20]; 22(3): [cerca de 5 p.]. Disponível em: https://doi.org/10.1590/2177-9465-EAN-2017-0169

15. Hardt M, Negri A. Bem Estar Comum. São Paulo: Record; 2016.

16. Declerck P. Los náufragos. Madrid: Asociación Española de Neuropsiquiatría; 2006.

17. Escorel S. Vidas ao léu: trajetórias de exclusão social. $1^{\text {a }}$ ed. Rio de Janeiro: Editora Fiocruz; 1999. 276 p.

18. Castelvecchi G. Quantas vidas eu tivesse, tantas vidas eu daria! São Paulo: Edições Paulinas; 1985.

19. Varanda W, Adorno RCF. Descartáveis urbanos: discutindo a complexidade da população de rua e o desafio para políticas de saúde. Saude Soc [Internet]. 2004 Apr [cited 2019 jun 4];13(1):56-69. Available from: http://www.scielo.br/scielo.php?script=sci_arttext\&pid=S0104-12902004000100007\&lng=pt\&tlng=pt
20. Natalino MAC. Estimativa da População em Situação de Rua no Brasil (Setembro de 2012 a Março de 2020) [Internet]. Nota Técnica - Diretoria de Estudos e Políticas Sociais/IPEA. 2020 [cited 2020 jun 25]. Available from: http://repositorio.ipea.gov.br/bitstream/11058/7289/1/td_2246.pdf

21. Cassigoli R. Morada y memoria: antropologia y poética del habitar humano. Madrid: Gedisa; 2011.

22. Sucasas JA. Emmanuel Levinas (1906-1995) - El absoluto ético. In: Ramos MB, Chico DP, editors. Un libro de huellas: aproximaciones al pensamiento de Emamanuel Levinas. Madrid: Trota; 2004.

23. Franco TB. As Redes na Micropolítica do Processo de Trabalho em Saúde. In: Pinheiro R, Mattos RA, editores. Gestão em Redes: práticas de avaliação, formação e participação na saúde. Rio de Janeiro: LAPPIS-IMS/ UERJ-ABRASCO; 2006.

24. Hino P, Monroe AA, Takahashi RF, Souza KMJ, Figueiredo TMRM, Bertolozzi MR. O controle de tuberculose na ótica de profissionais do Consultório na Rua. Rev Lat Am Enfermagem 2018;26:e3095.

25. Santos S, Souza Â, Abrahão A, Marques D. A visita domiciliar como prática de acolhimento no programa médico de Família/Niterói. Rev Pesqui Cuid é Fundam 2013; 5(2):3698-3705.

26. Merhy EE. Saúde: cartografia do trabalho vivo em ato. $3^{a}$ ed. Rio de Janeiro: Editora Hucitec; 2002. 145 p.

27. Franco TB, Bueno WS, Merhy EE. O acolhimento e os processos de trabalho em saúde: o caso de Betim, Minas Gerais, Brasil. Cad Saude Publica 1999; 15(2):345353.

28. Pinto AGA, Palácio MAV, Lôbo AC, Jorge MSB. Vínculos Subjetivos do Agente Comunitário de Saúde no Território da Estratégia Saúde da Família. Trab Educ Saude 2017; 15(3):789-802.

29. Hallais JAS, Barros NF. Consultório na Rua: visibilidades, invisibilidades e hipervisibilidade. Cad Saude Publica 2015; 31(7):1497-1504.

30. Rios AFM, Lira LSSP, Reis IM, Silva GA. Atenção primária à saúde frente à covid-19 em um centro de saúde. Enferm Foco 2020; 11(1):246-251.

Artigo apresentado em 29/10/2020

Aprovado em 08/10/2021

Versão final apresentada em 10/10/2021

Editores-chefes: Romeu Gomes, Antônio Augusto Moura da Silva 